\title{
Information Communication Technology (ICT) Utilization in Private Universities in Uganda: Exploring Strategies to Improve. A Case of Uganda Christian University
}

\author{
Stephen Kyakulumbye, Maurice Olobo, Vincent Kisenyi \\ Faculty of Business and Management, Uganda Christian University, Kampala, Uganda \\ Email:kyakusteve@yahoo.com,olobomaurices2005@yahoo.com,vkisenyi@yahoo.co.uk
}

Received September 26, 2012; revised November 6, 2012; accepted November 14, 2012

\begin{abstract}
The study was an extension of a similar study by [1] conducted among local government staff in Uganda and was extended among staff at Uganda Christian University. A total of 108 respondents out of the accessible 130 representing $83.0 \%$ response rate was realized after administering the study instruments over a period of two (2) weeks. Of the 108 respondents, $70.4 \%$ constituted staff in administration, $8.0 \%$ heads of sections and $21.6 \%$ academic staff. Data was analyzed using different statistical techniques which included descriptive statistics, mainly mean and standard deviation, Pearson Product Moment Correlation Coefficient to establish the relationships between variables and multiple regression analysis to establish causal influence of factors on ICT utilization. At bivariate level, organizational support systems, ICT infrastructure and users' perceptions had a strong relationship on ICT utilization. Multiple regression analysis revealed that only user perceptions (perceived ease of use) and user knowledge and skills had a significant causal influence on ICT utilization. The researcher Recommended that UCU strategic management cater for personnel ICT capacity building to improve their skills and therefore enhance ICT usability. Further research may consider segmenting staff by faculties and study how utilization levels differ using ANOVA. A comparative study can also be undertaken to assess UCU and any other private university.
\end{abstract}

Keywords: ICT Utilization; Management Support: Top Management Support \& Peer Support; ICT Infrastructure: Type of ICTs Accessed \& User Knowledge and Skills; User Perceptions: Perceived Benefits \& Perceived Ease of Use

\section{Introduction}

Governments and organizations worldwide are increasingly recognizing the need to facilitate access to public services through information exchange using Information and Communications Technologies (ICT) [1]. This paper presents problem statement, literature review, methodology, empirical findings, discussions, implications of the study, conclusions and recommendations.

\section{Problem Statement}

Information and Communication Technology utilization (ICT) capacity building in terms of human resources application development are enablers to equitable access to information and knowledge [2]. Knowledge is information that is interpreted and used by decision makers to meet their goals [3]. Various strategic managers at Uganda Christian University have complained about the utilization rates of available Information and Communication Technology (ICT) resources calling on staff to improve. Staffs have always been observed manually preparing students' lectures and conducting lectures without support of these abundantly available Information and Communication Technology (ICT) resources. This raises a question as to why, given the effort undertaken to put in place Information and Communication Technology (ICT) infrastructure, Information and Communication Technology (ICT) utilization seems to still be very low. The purpose of the study was therefore to explore strategies for Information and Communication Technology (ICT) uptake improvement among staff in private universities.

\section{Literature Review}

\subsection{Concept of ICT Utilization}

[1] stipulated that social activities are a crucial element of human life. People naturally live and work in communities. Under such an environment they turn to each other for help in case challenges are encountered. In promoting 
Information and Communication Technology (ICT) utilization for development, [4] urges that Information and Communication Technologies have potentially contributed to the democratization process in societies. This argument affirms that Information and Communication Technologies (ICT's) lead to an increase in the dissemination and access to information. If such information is appropriated by the population would lead to better informed decisions at micro and macro levels. [5] suggests that this rests on two premises: first that Information and Communication Technologies (ICT's) provide means of access to relevant information, and second, that information provided is assimilated, understood and applied as intended. Meanwhile, [6] affirmed that if these premises prove to be true, Information and Communication Technologies (ICT's) can raise awareness of citizens, facilitate participation in election processes through electronic pooling and spread democratic ideas across the globe. This therefore raises global awareness and expectations of citizens. The awareness generated enhances governments' dialogue between policy makers and the public, leading to greater accountability of those in power [7]. From the above arguments, the dimensions of Information and Communication Technology (ICT) utilization focused on in this study were information generation, storage, dissemination and application.

\subsection{Concept of Diffusion of Innovations Theory}

The study adopted the Diffusion of Innovations Theory (DoI). [1] argues that innovation is not a fashion but an essential element leading to long-term survival of organizations and a process of using new ideas to satisfy customers by converting new knowledge into products and services.

The DoI theory suits this study as it asserts that there are different forms of adopters who require organizational support as they interact with new innovations-ICT utilization to be able to change their different perceptions. The DoI theory adds that diffusion is governed by four main interacting elements: the innovation itself, communication channels, time and social system. These four components explain the process of change as determined by individuals, decision makers and the whole organization [8]. At Uganda Christian University, the key individuals are the staff who are viewed as heterogeneous agents interacting with their fellow peers in the institution. Human interaction involves communication and communication channels within the social system.

\subsection{Organizational Support Systems, User Perceptions, ICT Infrastructure and Utilization}

[9] assert that organizational support systems are the most investigated characteristics in organizational literature. They institutionalize how people interact with each other, how communication flows, and how power relationships are defined [10]. The support to organizational members reflects the value-based choices made by that organization [11]; it refers to how job tasks are formally divided, grouped, and coordinated. This study conceptualized the organizational support system as top management support and peer support in facilitating ICT utilization.

[1] defined top management support as the degree to which supervisors understand the importance of Information System (IS) function and the extent to which it is involved in Information System activities. In the context of ICTs, researchers who have adopted Roger's diffusion of innovations (DoI) theory consistently found that top management support is a strong determinant of ICT implementation success [12]. On the contrary, when [13] used the social cognitive theory of [1] to study the effect of top management support on ICT utilization, they found that top management did not affect ICT utilization at all. [14] argued that top management needs to establish willingness on the part of the organizational members by creating a climate of cooperation, demonstrating the efficacy of the new system and its benefits over the old ways of doing things. They add that the degree of acceptance or resistance to ICT projects will be due to the degree of top management support for the project. [15] pointed out that top management systems are critical issues in ICT utilization among users. Moreover, [15], as cited by [1], argues that engaging leaders in ICT trainings enables staff achieve higher potential in technology thereby enhancing ICT utilization. Meanwhile, [3] contends that no successful large scale change or ICT adoption effort has advanced without the support of top management. [1] in a study relating the school principal as a change facilitator for ICT, conclude that principals who take an active approach to innovations can foster an environment that has greater benefits to the users. Hence the leader's awareness, understanding and use of ICTs are essential for effective utilization of ICTs among staff. [16] noted that leaders should use technology as a model to fellow staff. [17] asserted that innovation diffusion needs a sharing and learning organizational environment among peer members. They add that learning and sharing knowledge among staff is important for innovation diffusion. [18] argues that learning is a key factor in innovation development. He suggests that training and development should be shifted to an experiential style of learning. [19] state that organizational learning occurs when people in an organization collaborate to share their different visions, knowledge, experiences and skills.

Organizational learning is a key ICT implementation strategy. ICT application development is frequently sub- 
ject to change. [20] assert that sharing tacit ICT knowledge among peers built from users' experience can improve ICT utilization within organizations. [21] explains that personal change may be best influenced by co-workers, friends, family and peers within an organization.

A study done by [17] using qualitative data among construction firms in Australia revealed that collegial help and mentoring is one way that knowledge sharing can most effectively occur because experienced users can give strong support by assisting novices to use ICT applications through knowledge transfer. They are supported by [22]; [13] that collegial help strongly influences change in an organization and argue that peer and collegial support is vital. Meanwhile, [1], in a study among Uganda local governments revealed that top management and peer support strongly and positively correlated with ICT utilization. On furthering their study using multiple regression analysis, their study further revealed a very strong casual effect between organizational support and ICT utilization. Moreover, available ICT infrastructure was alleged to be very vital in promoting organizational support.

[23] defined ICT infrastructure as everything that supports the flow and processing of information in an organization, including hardware, liveware, software, data and network components. [24] carried out a similar study in South Africa to investigate the factors that influence school level ICT adoption using the theory planned behavior. Their results using Spearman's correlation coefficient revealed that there was a strong, positive relationship between available ICT infrastructure and ICT utilization in schools. They assert that ICT infrastructure takes different forms which are addressed in the subsequent section.

In a study by [5] they highlight the following as ICTs in organization: standalone computers, networked or interconnected computers, remote access, electronic data interchange, Internet, websites, intranet and extranet. [25] defines differences in ICT access among people of the same social system as digital divide. Research on digital divide focuses first and foremost on the speed of various groups in adopting these new ICTs [26-29].

[30] argued that the relation of demographics and internet usage is one of the major research questions in the field of digital divide. Phenomena like these can be sub-summarized under the so-called "first order digital divide" [31]. The so-called "second order digital divide" addresses questions about different abilities to use the internet and draw advantages from its usage [32-34]. Less research has been done in a third dimension of adopting new technologies, i.e. the field of attitudes towards the internet, although these attitudes play an important role in adoption and in learning how to use this new medium.
Besides analyzing demographic characteristics of users and non-users, [30] denotes that there is need to focus on the question of attitudes, especially of non-users in comparison to users, to acquire a deeper understanding of the process of "digital divide" and the adoption of new technologies. Several reasons have been cited as causes of the digital divide. The 'digital divide' now implies "inequalities in access to the Internet, extent of use, knowledge of search strategies, quality of technical connections and social support, ability to evaluate the quality of information, and diversity of uses" [32].

Another way of defining the digital divide is by classifying individuals as either tech-savvy or less savvy [35]; [19] sees this phenomenon as giving the powerful more power over people, time and space, while eroding all powers of those who are marginalized or rendered offline. [36], through critical study of other scholars' works, categorized these factors as social, economical, and gender aspects of the divide.

[37] listed the following factors as some of the main contributors to Digital exclusion: Perceived or actual cost of personal computers, other equipment and Web-related phone calls; Access, as the lack of nearby or affordable facilities providing access to Web-ICTs and to build the skills and awareness to use them; Skills that include the lack of literacy, numeric and ICT skills; Cultural issues, which are the lack of critical mass of PC users among community, friends and family; Personal factors, which are the lack of confidence, credit card or bank account, fear of technology, no interest in the Internet and physiccal difficulties such as poor eyesight, or minimal dexterity and co-ordination. It is also asserted that user knowledge and skills are fundamental in enhancing ICT utilization.

[38] highlighted that small businesses tend to avoid integrating ICT into their businesses if it is seen as complex to use. This is not surprising because Small and Medium scale Enterprises (SMEs) always lack skills amongst workforce to use ICT [39]. [40] findings clearly indicated that ICT adoption is positively related to user knowledge and skills.

[41] suggested that it is very important for an organization to determine its employee's knowledge or skills of ICT because such knowledge or previous experiences may influence the organization's decision in adopting and utilizing ICT. They add that a manager's or owner's ICT knowledge and skills are likely to increase the opportunity for ICT utilization. [42] found that small business owner/managers are unlikely to adopt more sophisticated technologies if they are not familiar with the basic ones. [43] contradicted Reynolds, saying that CEO's tend to avoid basic ICT utilization and would rather have the sophisticated technology despite whether not they utilize it or not for having comparative advantage to other firms. 
He affirms that this technology adds them to the social class of the "haves".

The lack of suitable technical and managerial staff with sufficient ICT skills is another major barrier for SMEs in adopting ICT. [44] agrees that a skilled and knowledgeable workforce was closely linked with the successful implementation of technology. More researchers confirm the finding such as [45], who found that one of the strongest inhibiting factors for small firms to implementing information technology was the lack of information system knowledge and skills.

A study carried out by [41] on the factors that influence ICT adoption and usage in small and medium scale business enterprises (SMBs) in Nigeria analyzed data using linear regression analysis with significance level of $1 \%$ and found that there is a positive relationship between ICT knowledge and skills and ICT utilization. They assert that the relation between ICT knowledge and skills of the employees with ICT adoption and utilization is very significant.

[46] used a Theory of Planned Behaviour model among firms, in which they found that for business environments, user perception had a strong direct effect on an individual's intention to utilize ICT. The researchers provided support for [47]'s argument that in a real work environment, behavioral intentions are based primarily on performance-related elements, rather than on the individual's attitude towards the behavior.

Furthermore, [41] revealed that the greater the benefits perceived the higher the possibility of ICT utilization among SMEs. This study considers perceived benefits as one of the factors that could affect ICT utilization in organizations.

According to [48] it was found that ICT is able to improve information and knowledge management inside the firm and increase the speed and reliability of transactions for both Business-to-Business (B2B) and Business-to-Consumer (B2C) transactions. Besides that, they also explained the opportunities offered by ICT, including the exchange of real-time information and the closer relationships built with suppliers or business partners and customers. This study also found the possibility of immediate customer feedback according to the demand in the new markets. [49]'s study also stresses that the extensive use of ICT can allow micro-enterprises with ideas and technologies to remain small and profitable or generate substantial global sales by taking advantage of their intellectual property rights over the Internet.

On the other hand, [50] suggests that ICT is thought to contribute to overall growth in the long-term. Primary motivations for the SMEs to adopt new technologies (such as the Web) is the anticipated benefits these technologies will bring to the company [51]. [41] assert that SMEs have recognized the positive impacts of ICTs such as computer terminals, e-mail and Internet to the organization level as well as their applications on business performance. According to a study by [52], ICT implementtation in the organization which includes SMEs has the potential to reduce costs and increase productivity level. According to him, small firms might find cost-effectiveness a motivating factor to use Internet-commerce for improving communication with trading partners and consumers. [53] have given their expert opinion that ICT impacts include cheaper and faster communication, better customer and supplier relations, more effective and efficient marketing, product and service development and better access to information and training.

[54]'s study found a positive influence on ICT utilizetion in business that is able to increase business performance. Since there are many perceived benefits that have been made available through adoption with ICT, local governments are not taking advantage of ICTs. Therefore, perceived benefits were taken into consideration as one of the factors that affects ICT utilization in Mityana District Local Government.

[55] investigated the factors enabling ICT diffusion in construction firms in Malaysia. Their findings were that users' motivation to use IT/ICT was related to their attitude toward technology, such as perceived clear advantage of use, ease of use, relevance to their job, and professional credibility. They found the first two variables: clear advantage and ease of use to be strongly associated with their IT/ICT utilization. [56] found that a perceived ease of use is an important technology characteristic that generally influences innovation diffusion.

[47] proposed a Technology Acceptance Model (TAM) that predicts a user's intention to use ICT among students. Their results show that perceived ease of use is an essential variable motivating the use of word processing technology in an education environment. Similarly, [57] found that usefulness and ease of use motivates professsionals and managers to use computers and that users are more likely to use and adopt computer technology if they think that it is useable and it can improve their productiveity. This factor was investigated among Mityana District Local Government staff using Roger's DoI theory.

\section{Methodology}

\subsection{Research Design}

The research design was mainly quantitative. The data collection tool to back up this design was a close ended questionnaire.

\subsection{Data Collection Tool}

The items in the questionnaire were scored using a five point likert scale ranging from strongly agree to strongly 
disagree.

\subsection{Reliability and Validity}

To be sure of the measures, Cronbach's alpha co-efficient was computed for all variables and it confirmed the reliability of the instrument that had been used in the study because all variables showed values above 0.8 . Validity was obtained using Content Validity Index that was obtained as 0.906 above the acceptable limit of 0.7 .

\subsection{Data Analysis}

Data was analyzed using three levels. The first level had descriptive statistics mainly mean and standard deviation. The second level was for relational statistics using Pearson' Product Moment Correlation Co-efficient to establish the relationship between factors and ICT utilization. Thirdly on establishing whether relationship existed, hypotheses were tested using multiple regression analysis to establish the order of casual influence of factors on ICT utilization.

\section{Empirical Findings}

\subsection{Descriptive Statistics}

Pertaining ICT utilization, the Table 1 below shows that $45 \%$ of staff were in agreement with effective utilization, $5 \%$ were not sure while $50 \%$ were in disagreement. A mean of 2.4 reveals generally disagreement and a standard deviation of 0.6 does not show wide variations in their views.

Table 1. Aggregated descriptive statistics.

\begin{tabular}{cccccc}
\hline Variable & Agree & $\begin{array}{c}\text { Not } \\
\text { sure }\end{array}$ & Disagree & Mean & $\begin{array}{c}\text { Std. } \\
\text { Dev }\end{array}$ \\
\hline $\begin{array}{c}\text { TIC (DV) } \\
\text { utilisation } \\
\text { Organizational } \\
\text { support }\end{array}$ & 45 & 5 & 50 & 2.4 & 0.6 \\
$\begin{array}{c}\text { ICT infrastructure } \\
\begin{array}{c}\text { User perceptions } \\
\text { User pertion }\end{array}\end{array}$ & 36 & 3 & 64 & 2.3 & 0.5 \\
\hline
\end{tabular}

\subsection{Relational Statistics of the Variables}

Before relational empirical statistics, the study established the linearity of results. This is one of the Pre conditions for computation of Pearson's Product Moment Correlation Coefficient. The scatter plots revealed a strong positive linear relationship between factors, dimension and ICT Utilization due to the fact that a line of best fit could be drawn through the variables. This necessitated computing Pearson's Product Moment Correlation Coefficients and results are shown in Table 2 below.

The results from Table 2 reveal that top management support has a weak correlation as the sig. value generated is slightly above the acceptable limits of 0.05 and 0.01 at $95 \%$ and $99 \%$ levels of significance. Meanwhile, peer support, another measure of organizational support, revealed statistically significant results of sig. value of 0.015. Additionally, ICT infrastructure was measured by type of ICT and user knowledge or skills. Type of ICT accessed and user skills revealed a sig. value of 0.000 which depicts a very strong positive relationship with ICT adoption. This implies that user knowledge and type of ICT accessed are critical predictors of ICT uptake.

User perception was another factor used to determine ICT adoption, and it was measured by perceived benefits and perceived ease of use. The study revealed sig. values of 0.007 and 0.000 for perceived benefits and perceived ease of use, respectively. This implies that perceived benefits from ICT and perceived ease of use strongly relate to ICT uptake.

\subsection{Multiple Regression Results}

On establishing that the various dimensions of factors fully substantiated ICT uptake, the researcher advanced to establishing whether the relationship that exists is a cause and effect relationship by computing a multiple regression analysis basing on the linear regression model of $Y=\beta 0+\beta 1 X 1+\beta 2 X 2+\cdots+\beta n X n+\varepsilon$ where $Y$ is ICT utilisation, $X(1-n)$ are the factors (organisational sup port, users perceptions and ICT infrastructure), $\beta 0$ is the constant, $\beta(1-n)$ are the regression coefficients or effect of the framework dimensions. Here, hypotheses are to be

Table 2. Pearson's product moment correlation coefficient.

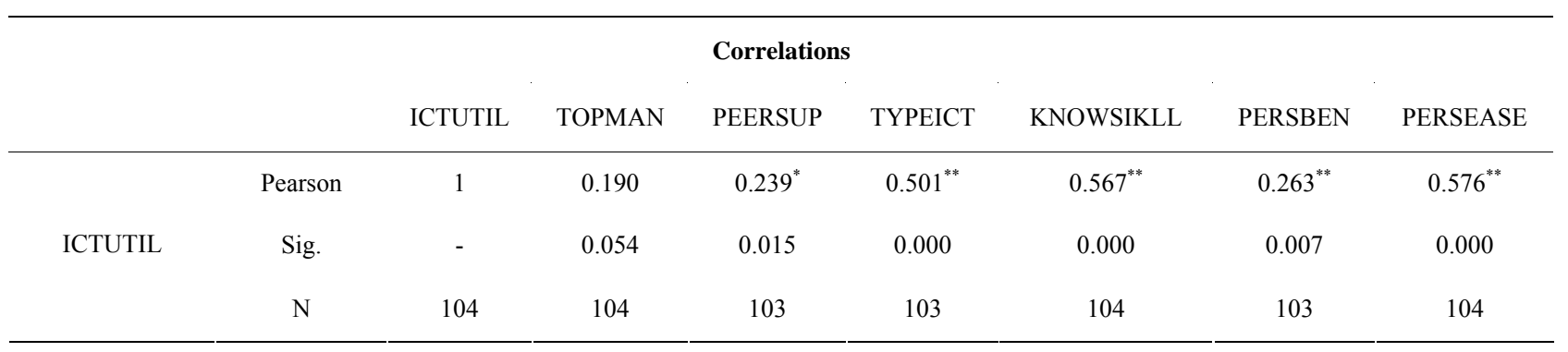

"Correlation is significant at the 0.05 level (2-tailed); ${ }^{* *}$ Correlation is significant at the 0.01 level (2-tailed). 
rejected or upheld. Table 3 below is the results.

The sig. value $(0.025)$ reveals only a respondent's knowledge and skills the cause for ICT adoption. The higher one's knowledge and skills is, the higher the ICT utilization in the university setting. Perceived ease of use was also substantiated to determine ICT utilization. Additionally, based on the beta value, the factors dimensions are ranked in order of cause to ICT adoption: knowledge and skills is ranked first (beta value 0.326), followed by perceived ease of use (beta value 0.264), then type of ICT accessed (beta value 0.082), peer support (beta value 0.071 ) and lastly perceived benefits (beta value -0.012).

\section{Discussions}

The study revealed that organizational support did not have a strong relationship and positive influence on ICT utilization. The results for this study were in disagreement with [1] who asserted that top management was a strong predictor of ICT utilization among local government staff.

The second objective sought to find out the influence of ICT infrastructure on ICT utilization in Universities. The results revealed that ICT infrastructure (type of ICT accessed) did not have a significant influence on its utilization. The results of this study are in agreement with Rogers' theory of diffusion of innovations which guided this study. It contends that members of a social system adapt to a new innovation to utilize ICT only when they are allowed to have access to that innovation and are empowered through continuous communicationto utilize it by decision makers. This, therefore, suggests that it is not only a matter of having rich ICT in frastructure, but also empowering users to utilize it through

Table 3. Casual effect of the framework dimensions.

\begin{tabular}{rcccc}
\hline \multirow{2}{*}{ Model } & \multicolumn{3}{l}{ Standardized Coefficients } & \\
\cline { 2 - 5 } & $\mathrm{B}$ & Beta & $\mathrm{t}$ & Sig. \\
(Constant) & 0.586 & & 1.412 & 0.161 \\
TOPMAN & 0.030 & 0.037 & 0.361 & 0.719 \\
PEERSUP & 0.061 & 0.071 & 0.673 & 0.502 \\
TYPEICT & 0.081 & 0.082 & 0.659 & 0.511 \\
KNOWSIKLL & 0.313 & 0.326 & 2.271 & 0.025 \\
PERSBEN & -0.011 & -0.012 & -0.127 & 0.900 \\
PERSEASE & 0.256 & 0.264 & 1.942 & 0.050 \\
\hline
\end{tabular}

a. Dependent variable: ICTUTIL skill development (retooling) as the revelation of the study by [1].

The correlation results of this study are further in disagreement with [24] who conducted a similar study in South Africa to investigate factors that influenced school level adoption of ICTs using the theory of planned behavior. The study revealed that there was a strong positive relationship between available ICT resources and ICT utilization in schools. On furthering their analysis using multiple regressions, their study revealed similar results to those of this study, concluding that as much as a strong relationship existed, there was no significant influence at all.

The third objective sought to investigate the influence of users' perception on ICT utilization. From Pearson's correlation results the study revealed a strong and significant relationship and regression analysis and also revealed a significant influence on ICT utilization. The results of this study are in agreement with [46] who asserted that in a real work environment, behavioral intentions are based primarily on performance related elements, rather than on the individuals' attitudes towards a behavior. This, therefore, implies that users of such departments will consider ICTs if they envisage value addition to their job roles. The theory of diffusion of innovations that guided this study declares that users will adapt to an innovation and utilize it when effort is made to persuade and create awareness (knowledge) of them as an effort to change their negative perception that results in rejection of an innovation. Meanwhile, the results of this study confirm [41] findings which also revealed that the greater the usability, the higher the possibility of ICT adoption and utilization among SMEs. Similarly, [57] found that ease of use motivates professionals and managers to use computers and that they were more likely to use computer technology if they think that it is useable and can improve their productivity.

\section{Implications of the Study}

The university management needs to put in place an ICT awareness campaign and sensitization addressed by departments and faculties to enhance ICT utilization. Additionally, strategic managers need to conduct a capacity building needs assessment in the university to ensure ICT infrastructure put in place is of benefit to staff. There is need to implement regular ICT workshops, training programs, seminars and conferences within the university to raise ICT awareness.

Top Management needs to offer timely communication in order to create awareness of the ICT innovations so that staff can utilize them; this can be done by drafting memos and circulating them to departmental heads about new ICT implementation: there is need for a bottom to top information system planning during drafting of an- 
nual budgets for ICT implementation; that is to say, ICT priority areas should be clearly articulated in the sectoral plans and budgets.

\section{Conclusion}

All in all, this study does not disqualify previous contributions by various studies which revealed that available ICT infrastructure in an organization has a positive and significant influence on ICT utilization but sought to compliment these earlier studies in order to have ICTs in Universities effectively utilized. It also does not draw a final ruling that the factors that this study investigated are the only determinants of ICT utilization. There could be other factors influencing ICT utilization that may be studied by another scholar.

\section{Acknowledgements}

This study has been made possible by the honest participation and cooperation of the Administrative and teaching staff at Uganda Christian University, Bishop Tucker Campus Mukono. Special thanks also go to the Dean of the faculty of business for the support extended to this study.

\section{REFERENCES}

[1] S. Kyakulumbye, M. B. Muhenda and A. M. Namanya, "ICT Utilization in Uganda Local Governments: Why Low Uptake?" LAP Lambert Academy Publishing, Deutshland, 2012.

[2] Vision2040, "National Planning Authority Manual," Citizens' Guide to the National Development Plan 20112040, p. 32.

[3] M. Fullan, "The Moral Imperative of School Leadership," Thousand Oaks, Corwin, 2003.

[4] S. G. Hadden, "Democracy on the Electronic Frontier," In: G. Chapman, Ed., Beyond the Endless Frontier, MIT Press, New York, 1996.

[5] J. Forth and G. Mason, "ICT Adoption \& Utilization, Skills Constraints \& Firm Level Performance," Evidence from UK Bench Marking Survey, 2004.

[6] A. Coleman, M. E. Herselman and S. J. Jacobs, "Factors Influencing the Utilization of the Public Internet Terminal System in Two Rural Communities," 2008.

[7] C. R. Kedzie, "Democracy and Network Interconnectivity, Internet," 1995.

[8] J. Huang and M. Kapur, "Diffusion of Pedagogical Innovations as a Complex Adaptive Process," Agent Based Modeling as Research, 2007.

[9] M. Zhang, J. McCullough and Y. W. Ren, "Effects of Organizational Structure and IT Capability in Emerging Markets," Journal of Information System, Vol. 56, No. S3, 2004.

[10] Hall, "Organizational Characteristics and Funding Environments," A Study of Population of United Way, 1987.
[11] Quinn, "Beyond Rational Management; Mastering Paradoxes and Competing Demands of High Effectiveness," Jossey-Bass, San Fancisco, 1988.

[12] K. Al-Garbi and S. M. Al-Turki, "Factors Influencing the Factors of Intranet in Knowledge Management in Developing Organizations," International Association for Management of Technology (IAMOT), 2001.

[13] D. R. Compeau and C. A. Higgins, "Computer Self-Efficacy," Development of a Measure Computer Self-Efficacy, Concordia University, John Molson School of Business, Montréal, 1995.

[14] J. K. Pinto and I. Millet, "Successful Information System Implementation: The Human Side," 2th Edition, Project Management Institute, Inc., 1999.

[15] R. Phelps, “A Constructivist Approach to Professional Development in ICT Leadership. Creating a Learning Community," Australian Computers in Education Conference, Hobart, 2000, p. 29.

[16] W. C. Hope, R. Kelly and J. Guyden, "Technology Standards for School Administration: Implication for Administrator Preparation Programs," IT and Teacher Educational Conference, San Diego.

[17] V. Peansupap and D. H. Walker, "Factors Enabling ICT Diffusion and Actual Implementation in Construction Organizations," 2005.

[18] D. M. Rogers, "The Challenge of Fifth Generation Research \& Development," Research Technology Management, 1996.

[19] S. Grahaman, "Bridging Urban Digital Divides," 2002.

[20] P. Attewell, "Technology Diffusion and Organizational Learning," The Case of Business Computing; Organizational Science, Vol. 3, No. 1, 1992, pp. 1-19.

[21] J. R. Carlopio, "Implementation: Making Workplace Innovation and Technology Change Happen," McGraw-Hill Book Company Australia Pty, Ltd., 1998.

[22] P. Senge, "The Dance of Change: The Challenge of Sustaining Momentum in Learning Organization," Nicolas Brealey Publishing, London, 1999.

[23] K. E. Perrlson and C. S. Sunders, "Managing and Using Information Systems," A Strategic Approach Third Edition United States of America, 2006.

[24] L. Miller, M. Naidoo and A. Chigona, "An Empirical Survey on Domestication of ICT in Schools in Disadvantaged Communities of South Africa," 2006.

[25] B. Mehra, C. Merkel and A. Bishop, "The Internet for Empowerment of Minority and Marginalized Users," New Media and Society, Vol. 6, No. 6, 2004, pp. 781-802.

[26] R. Anderson, T. Bikson, and B. Mitchell, "Universal Access to E-Mail: Feasibility and Social Implications," Santa Monica, 1995.

[27] J. Katz and R. Rice, "Social Consequences of Internet Use: Access, Involvement, and Interaction," Massachusetts Institute of Technology (MIT) Press, Cambridge, 2002.

[28] J. Katz, R. Rice and P. Aspden, "The Internet, 1995-2000: Access, Civic Involvement and Social Interaction," The American Behavioral Scientist, Vol. 45, No. 1, 2001, pp. 
405-423.

[29] H. Selhofer and T. Husing, "The Digital Divide Index-A Measure of Social Inequalities in the Adoption of ICT. Bonn," 2002.

[30] E. Donart, R. Brandtweiner and J. Kerschbaum, "Attitudes as Predictors for Internet Usage; A Tripartite Model of Attitude Measurement," Proceedings of the Computer Science and IT Education Conference, 2007, p 192.

[31] S. Dewan and F. Riggins, "The Digital Divide: Current and Future Research Directions," Journal of the Association for Information Systems, Vol. 6, No. 12, 2005, pp. 298337.

[32] P. Di Maggio, E. Hargitta, W. R. Newman and J. Robinson, "Social implications of the Internet," Annual Review of Sociology, Vol. 27, 2001, pp. 307-336.

[33] E. Harggitai, "Second Level Digital Divide: Differences in the People's Online Skills," First Monday, Vol. 7, No. 4, 2002.

[34] E. Hargittai, "Informed Web Surfing: The Social Context of User Sophiscation," Society Online: The Internet in Context, 2003, pp. 257-274.

[35] D. Hoffman, T. Novak and A. Schlosser, "The Evolution of Digital Divide: How Gaps in Internet Access May Impact Electronic Commerce," 2004.

[36] S. Rishika, "The Causes and Trends of the Digital Divide," Candidate for M.Sc., 2006.

[37] A. Malina and A. Macintosh, "Bridging the Digital Divide," IGI Publishing Hersley, 2004.

[38] R. MacGregor, D. Bunker and L. Viazalic, "A Basic Model of Electronic Commerce Adoption Barriers: A Study of Regional Small Businesses in Sweden and Australia," Journal of Small Business and Enterprise Development, Vol. 12, No. 4, 2005, pp. 510-527.

[39] Spectrum, "Moving into Information Society," HMSO, London, 1997.

[40] W. Paul and B. Pascal, "Factors Affecting the Adoption of Intranet and Extranets by SMEs," A UK Study Research Memoranda 026, Maastricht: MERIT Maastricht Economic Research Institute on Innovation and Technology, 2003.

[41] S. A. Syed and M. K. N. Mohammad, "ICT Adoption in SMEs: An Empirical Evidence of Service Sectors in Malysia," An International Journal of Business and Management, 2009.
[42] W. Reynolds, W. Savage and A. Williams, "Your Own Business: A Practical Guide to Success," ITP, 1994.

[43] S. B. Riffat, "SME Survey: What Keeps You up at Night?" Computer Business Review, 2007.

[44] Allison, "ICTs Skills Challenges in SMEs," 1999.

[45] P. B. Cragg and M. King, "Information System Sophiscation and Financial Performance of Small Engineering Firms," European Journal on Information System, Vol. 5, No. 2, 1992, pp. 24-33,

[46] S. Taylor and P. A. Todd, "Understanding IT Usage: A Test of Competing Models," IS Research, Vol. 6, 1995, pp. $144-176$

[47] F. D. Davis, R. P. Bagozzi and P. R. Warshaw, "User Acceptance of Computer Technology," Department of Information Systems, London School of Economics, 1989.

[48] Organization of Economic Co-Operation and Development, "The Economic Impact of ICT-Measurement, Evidence and Implications," OECD, Paris, 2004.

[49] K. Sakai, "Global Industrial Restructuring: Implications for Small Firms," STI Working Papers 4, Organization of Economic Co-Operation and Development, Paris, 2002.

[50] M. Pahjola, "IT and Economic Development. An Introduction to Research Issues," Research Paper 153, World Institute for Development Economics Research, 1998.

[51] G. Premkumar and M. Roberts, "Adoption of New IT in Rural Small Business," Omega, Vol. 27, No. 4, 1999, pp. 467-484.

[52] A. Lymer, "The Internet and Small Businesses: A Study of Impacts," Fifth European Conference on IS, Colorado, 1997, pp. 145-162.

[53] G. Lauder and A. Westhall, "Small Firms Online," Commissions on Public Policy and British Business, 1997.

[54] A. Barua, C. H. Kriebel and T. Mukhopadhyay, "Its and Business Value: An Analytic and Empirical Investigation," Information System Research, Vol. 6, No. 1, 1995. pp. 3-23.

[55] V. Peansupap and H. T. Walker, "Strategic Adoption of ICT," Case Studies of Construction Contractors, 2005.

[56] E. M. Rogers, "Diffusion of Innovations," 5th Edition, Free Press, New York, 2003.

[57] M. Igbaria, S. Parasuraman and J. J. Baroudi, "A Motivational Model of Micro Computer Usage," Journal of MIS, Vol. 13, No. 1, 1996, pp. 127-143. 